\title{
Macroeconomic equilibrium and reform in a transitional economy
}

\author{
John Bennett ${ }^{\mathrm{a}, *}$, Huw David Dixon ${ }^{\mathrm{b}}$ \\ "Department of Economics, University College of Swansea, Singleton Park, Swansea SA2 8PP, UK \\ b Department of Economics and Related Studies, University of York, Heslington, York YO1 5DD, UK
}

Received October 1992; final version received June 1994

\begin{abstract}
We build a general equilibrium macro model of a transitional economy to reflect four stylized facts. Among these are that central planning has left a legacy of highly concentratcd industry and a residue of price controls and rationing. An 'almost' Classical Dichotomy obtains in the model: monetary expansion leaves output and employment unchanged (despite the existence of unemployment), though leisure time declines. However, the economy displays a high degree of complementarity between the state-controlled and private sectors, giving rise to Keynesian multiplier effects. We also analyse the effects of price-liberalization and privatization on the properties of the economy.
\end{abstract}

JEL classification: D43; E10; P21; P51

Keywords: Transitional economy; Imperfect competition; Macroeconomics

\section{Introduction}

During the transition from communism to capitalism the economies of Eastern Europe and the former Soviet Union constitute new forms of economic system and face a combination of problems that is without historical precedent. Consequently, in the formal analysis of transitional economies it is inappropriate simply to take existing models of market economies and introduce some amendments. Rather,

\footnotetext{
* Corresponding author.
} 
new models are required that are designed specifically to encapsulate the characteristics of these economies. In this paper we formulate a model of a transitional economy in order to examine its macroeconomic properties and the general equilibrium interactions between its constituent sectors. We begin by setting out four 'stylized facts' that are intended to represent the recent situation in the countries of the CIS in particular but are also relevant, in varying degrees, to the economies of Eastern Europe. In the paper we develop a macroeconomic model that is consistent with these facts and then we consider the implications of market-oricntcd reforms (price liberalization and privatization). Our analysis is an exercise in comparative macroeconomic systems within the context of the alternatives facing the governments of transitional economies today.

Stylized Fact No. 1. The firms inherited from the communist era are highly monopolistic

Under communism industrial production was highly concentrated, partly for economies of scale and partly to simplify the resource allocation problem facing the planners. In the USSR, for example, the IMF et al. (1991) note that, for a breakdown of 344 industrial product groups, the largest producer made $50-75 \%$ of the output in 83 cases, and more than $75 \%$ in 126 cases. Similar figures hold for other transitional economies (Landesmann and Székely, 1991). The break-up of large plants is not always technically feasible (Kroll, 1991) and, in any case, it is often argued that a more vigorous market system will develop if demonopolization is left to occur through entry (IMF et al. (1991) on the USSR; Kornai (1990) on Hungary; Lipton and Sachs (1990) on Poland).

Stylized Fact No. 2. A large proportion of these firms are effectively independent from state control

All transitional economies aim to privatize the bulk of state-sector production, though practical difficulties have generally made progress slow. Thus, for example, the IMF (1992b) acknowledges that the state sector in Russia is set to play a significant role for some time to come. Unfortunately, there is no generally accepted way of modelling firms in this context (see Estrin and Hare, 1992), but it is clear that many firms are using commercial criteria, with control (de facto if not de jure) of their own production and pricing decisions and the distribution of profits. Consequently, firms have set prices to exploit their monopolistic positions (see, e.g., Hare and Révész, 1992).

Stylized Fact No. 3. There is an excess supply of labour

Significant open unemployment has appeared in most transitional economies (OECD, 1992), and although the official unemployment rate in Russia was only 
about $1 \%$ at the end of 1992 this figure did not include hidden unemployment, particularly forced vacations and reductions in hours (Russian Economic Trends, 1992). As commercialization and privatization proceed, we may expect further redundancies to occur. It may therefore be assumed that, for the foreseeable future, these economies will have an excess supply of labour.

\section{Stylized Fact No. 4. Extensive price liberalization has taken place, but the prices of some goods have been kept below market-clearing levels}

The price liberalization carried out in early 1992 in Eastern Europe (except Albania) and the former USSR is well documented (e.g. IMF, 1992a). However, in each country the prices of some basic consumption goods, although raised, have been kept below market-clearing. An informal non-price rationing scheme has been used, households competing to buy the goods by searching and queuing. (As Osband (1992) notes, although other (formal) rationing schemes may nominally have been used, they have been difficult to administer and have rarely eliminated the need to search and queue). The proportion of the consumption goods market with state-imposed price controls ranged from about $20 \%$ in Kazakhstan to $10 \%$ in Russia and only 5\% in Czechoslovakia (IMF, 1992a). Additionally, in the case of Russia many local authorities have imposed further price controls and rationing (Aslund, 1993). According to Doyle (1993) the local authorities may be using their relatively favourable fiscal position to try and buy popularity with such controls.

In Section 2 we formulate a simple general equilibrium macroeconomic system that is consistent with these stylized facts. We divide the economy into two sectors, in each of which there is increasing returns to scale and firms are 'large'. The 'state-controlled' sector produces a parametrically given quantity of basic consumption goods for which the nominal price is fixed at a level below market-clearing. ${ }^{1}$ Households compete to buy the good by an expenditure of time, which may be interpreted as search and queue activity. The other production sector is 'oligopolistic', consisting of commercially-run firms on which no effective behavioral constraints are imposed by the government. We allow for firms in this sector to be either state- or privately-owned; in the latter case their net of tax profits are distributed directly to households. Throughout, we assume that the labour market is competitive, with labour always available at the endogenously-determined money wage rate.

\footnotetext{
${ }^{1}$ The classification of rigidity as nominal or real is of course crucial in theory, although not obvious in practice. Typically, regulations refer to nominal prices, but these are reviewed on a more or less regular basis. Full real rigidity would require instantaneous and continuous full indexation, which clearly does not occur in transitional economies. We have opted for the other extreme of complete nominal rigidity, which is more realistic for short-run purposes. However, throughout the paper we also note how our conclusions would be affected if the rigidity were real, which might be the more appropriate assumption for longer run analysis.
} 
In Section 3 we investigate some properties of the macroeconomic equilibrium for this model, and in Sections 4 and 5 we consider how the system operates if particular forms of liberalization are undertaken. In Section 4 we suppose that there is price liberalization in the sense that the predetermined output of the state-controlled sector is sold at a market-clearing price. In Section 5 we assume, instead, that the state-controlled sector is privatized, and that, because it produces basic consumption goods, it is subject to price-cap regulation: quantity is liberalized, but price is not.

There are some significant omissions from our list of stylized facts. First, we do not allow for the small-scale production sector found in transitional economies (see, e.g., IMF, 1992b). However, in an earlier version of this paper (Bennett and Dixon, 1993) we showed that the analysis generalizes to incorporate such a sector without affecting our results significantly. Second, we have not mentioned the large fall in output that has been observed in transitional economies. Detailed consideration of the reasons for this fall are beyond the scope of the present analysis (see IMF, 1992b); but we are able to comment briefly on the role played by general equilibrium interactions between sectors in this context. Third, for simplicity we have not taken into account the progressive liberalization of foreign trade in transitional economies. As such liberalization occurs the degree of market power exercised by domestic firms would be reduced. However, we would suggest that a variety of factors (transport costs, limited foreign exchange earnings, idiosyncratic preferences, cultural and legal heterogeneity, political uncertainty and other non-tariff barriers) will lead to the persistence of some domestic market power (a similar argument applies for Western economies).

\section{The basic model}

There is a large number of industries, which we classify into two sectors. The 'state-controlled' sector, the remnant of central planning, supplies a predetermined quantity of goods at fixed nominal prices. The 'oligopolistic' sector is outside state control; its price and output decisions are made according to commercial criteria. The labour market is competitive, with perfect labour mobility. We shall aggregate within each sector, phrasing the analysis in terms of a representative state-controlled industry and a representative oligopolistic industry, each making a single homogeneous good.

\subsection{Households}

There is a large number of identical households. The representative household has an endowment of $H$ units of time, of which it spends $N$ working, $Q$ in queuing and search activity ('queuing' for short), and $Z$ on leisure:

$$
N+Q+Z=H \text {. }
$$


We assume that $N$ is exogenous for the household and that the disutility of working and queuing is $\theta(N+Q)$, where $\theta$ is constant.

Household consumption of the outputs of the state-controlled sector (the 's-sector') and the oligopolistic sector (the 'o-sector') is $x^{\mathrm{s}}$ and $x^{\mathrm{o}}$, respectively. To represent that a large proportion of necessities are produced in the s-sector, we include in the utility function a 'subsistence' element $\bar{x}$ of the s-sector good (as in a Stone-Geary function). Utility is given by

$$
u=\left[U\left(x^{s}-\bar{x}, x^{\circ}\right)\right]^{c}(M / p)^{1-c}-\theta(N+Q) .
$$

$U$ is a degree-one homogeneous sub-utility function; $p$ is a cost-of-living index for $U$; and $M$ is the household's terminal money balance. We assume throughout that $x^{\mathrm{s}} \geqslant \bar{x}$.

Let $q^{\text {s }}$ denote the full price (to be defined) of a unit of s-sector output and let $p^{\circ}$ denote the money price of a unit of o-sector output. The index $p$ is a function,

$$
p=P\left(q^{s}, p^{o}\right),
$$

which is homogeneous of degree one, with $U$ normalized such that $\gamma=P(\gamma, \gamma)$. 'This index measures the 'full' money cost of a unit of $U$. We shall interpret $u$ as the household's mixed (direct and indirect) utility function in which the nominal terminal money balance $M$ is used to buy future consumption. In this case the cost-of-living deflator used to obtain the real balance represents future prices (in full terms as appropriate). For simplicity, we assume that the household expects current and future prices to be identical, although the results would not be changed so long as future prices were proportional to current prices.

To specify the household budget constraint we must consider the distribution of profits. We suppose that s-sector money profit $\pi^{\mathrm{s}}$ accrues entirely to the state, but that the household receives a proportion $\beta(0 \leqslant \beta \leqslant 1)$ of o-sector money profit $\pi^{\circ}$, the proportion $(1-\beta)$ accruing to the state as profits tax. Let $w$ and $p^{\mathrm{s}}$ denote the money wage and money price of a unit of s-sector output, respectively. If the household's initial money holding is $\bar{M}$ and it pays the lump-sum tax $T$, we can write its money budget constraint as

$$
\bar{M}-T+w N+\beta \pi^{\mathrm{o}}=p^{\mathrm{s}} x^{\mathrm{s}}+p^{\mathrm{o}} x^{\mathrm{o}}+M .
$$

There is no public consumption of goods: the only source of demand is domestic households, whom we assume buy goods only for current consumption, not for hoarding. Total s-sector output is fixed at a level at which there is an aggregate excess demand, given $p^{\mathrm{s}}$ and the other parameters in the model. ${ }^{2}$ To buy the s-sector good it is necessary to spend time queuing as well as paying the money price. Let $t$ denote the expenditure of time necessary to obtain one unit of

\footnotetext{
${ }^{2}$ In practice, some of the output produced by the state-controlled sector has been of little use and has been left unsold. To take this into account, our $x^{\mathrm{s}}$ may be regarded as that part of s-sector output that is useful - and hence is rationed through queues.
} 
the s-sector good. Following several recent contributions, we suppose $t$ is independent of the amount bought by an individual household, but adjusts to equate the aggregate demand for the s-sector good with the supply forthcoming; i.e., $t$ is market-clearing. ${ }^{3}$ A strict interpretation would be that, as often happened in the USSR, each time a consumer reaches the front of a queue he or she is only allowed to purchase one unit and must return to the back of the queue to purchase another unit. An alternative approach, taken by Weitzman (1991), is to suppose that on reaching the front of a queue a consumer can buy an unlimited amount (subject to a budget constraint). Our approach, which has the benefit of simplicity, seems more justified if the period under consideration is sufficiently long that repeat purchases are necessary. Return to the back of the queue can then be regarded as occurring at a different date within the period. The total time spent in buying $x^{\mathrm{s}}$ units in our model is

$$
Q=t x^{s} \text {. }
$$

The household thus chooses $\left(x^{\mathrm{s}}, x^{\mathrm{o}}, M, Q\right)$ to maximize (2.2) subject to (2.1) and (2.3)-(2.5), treating as parameters $\left(p^{\mathrm{s}}, p^{\mathrm{o}}, w, t, \bar{M}, N, T, \pi^{\circ}\right)$.

\subsection{Macroeconomic relationships}

Before considering how the household determines its expenditure it is helpful to set out some macroeconomic relationships. We begin with the government's finances. We have already assumed that it receives all of $\pi^{\mathrm{s}}$ and a proportion $1-\beta$ of $\pi^{\circ}$ and that it levies a lump-sum tax $T$ on the household. Thus, the government deficit is

$$
D=-\left[T+\pi^{\mathrm{s}}+(1-\beta) \pi^{\mathrm{o}}\right] .
$$

Transitional economies tend to have a persistent deficit (see OECD, 1992), partly because of the losses made by s-sector firms. Thus, we may regard $D$ as positive and $\pi^{\mathrm{s}}$ as negative. As financial markets are rudimentary, we assume $D$ is financed entirely by money creation:

$$
M-\bar{M}=D \text {. }
$$

Turning to the flow of nominal national income and expenditure, $Y$,

$$
Y \equiv w N+\pi^{\circ}+\pi^{\mathrm{s}}=p^{\mathrm{s}} x^{\mathrm{s}}+p^{\circ} x^{\mathrm{o}}
$$

To specify the equilibrium level of $Y$ we refer to the first stage of the household's budgetary process. From (2.4) it has available the amount $\bar{M}-T+$ $w N+\beta \pi^{\circ}$. Because $[U(\cdot)]^{c}(M / p)^{1-c}$ is Cobb-Douglas, the first budgetary stage

\footnotetext{
${ }^{3}$ See Stahl and Alexeev (1985), Sab (1987), Boycko (1992), Osband (1992) and Bennett (1994), among others. See Boycko for further discussion.
} 
involves choosing to spend the proportion $c$ of this amount on goods and the proportion $(1-c)$ in accumulating of real money balances. ${ }^{4}$ We can therefore write the macroeconomic identity that the flow of income equals the flow of expenditure as $Y=c\left(\bar{M}-T+w N+\beta \pi^{\circ}\right)$, which, with Eqs. (2.6)-(2.8), gives

$$
Y=\frac{c}{1-c}(\bar{M}+D) \text {. }
$$

Thus equilibrium nominal national income is determined by a standard income-expenditure process. Because deficits are financed entirely by money creation, changes in $\bar{M}$ and $D$ have identical effects on $Y$. For simplicity, we shall assume that $D$ is predetermined by the government; from (2.6) the $D$-target is achieved by manipulation of $T$ and $\beta$.

\subsection{Goods demands}

We now turn to the second stage of the household's budgetary process, which can be expressed succinctly in 'full' terms. The full price of the s-sector good is

$$
q^{\mathrm{s}} \equiv p^{\mathrm{s}}+\theta P\left(q^{\mathrm{s}}, p^{\mathrm{o}}\right) t .
$$

This is the money price $p^{s}$ plus the cost, in money terms, of the time required to buy a unit of the s-sector good (see Sah, 1987; Bennett, 1994). Note that $q^{s}$ enters both sides of (2.10). The terms 'virtual' and 'full' are often used interchangeably in the literature, but we shall refer to $\theta P(\cdot) t$ as the 'virtual' element of the 'full' price $q^{\text {s. }}{ }^{5}$

At the second budgetary stage the household allocates its money expenditure $Y$ between the two goods. Since $U$ is homothetic, the budget share functions are homogeneous of degree zero in $q^{\mathrm{s}}$ and $p^{\mathrm{o}}$. Because $q^{\mathrm{s}}$ is a full price the 'expenditure' on the s-sector good that enters its budget share must be measured in terms of the full price. Also, as the full price $q^{\mathrm{s}}$ contains a virtual element $\theta P t$, the 'budget' referred to here must include an adjustment for virtual purchasing power (see Sah, 1987). Furthermore, as $x^{s}-\bar{x}$, rather than $x^{\mathrm{s}}$, is the first

\footnotetext{
${ }^{4}$ The assumption that money demand is a constant proportion of $\bar{M}-T+w N+\beta \pi^{\circ}$ is inappropriate if there is a high underlying rate of inflation, as is typically found in the early stages of the transition from communism. However, we do not believe that the additional effects that would enter the analysis if this assumption were dropped would be significantly different from those that would obtain in the analysis of a non-transitional (capitalist) economy. For simplicity, therefore, we exclude such effects.

${ }^{5}$ The full price approach has also been used to measure 'true' rates of inflation in communist economies by Feltenstein and Farhidian (1987), Portes and Santorum (1987), Feltenstein et al. (1990) and Feltenstein and $\mathrm{Ha}(1991)$.
} 
argument of $U$, the expenditure on the s-sector good must be calculated net of the cost of buying $\bar{x}$, and the budget must be measured net of this cost. Thus, we have

$$
\begin{aligned}
& q^{\mathrm{s}} x^{\mathrm{s}}=q^{\mathrm{s}} \bar{x}+\alpha\left(\frac{p^{\circ}}{q^{\mathrm{s}}}\right)\left(F-q^{\mathrm{s}} \bar{x}\right), \\
& p^{\mathrm{o}} x^{\mathrm{o}}=\left[1-\alpha\left(\frac{p^{\mathrm{o}}}{q^{\mathrm{s}}}\right)\right]\left(F-q^{\mathrm{s}} \bar{x}\right), \\
& F \equiv Y+\theta P(\cdot) t x^{\mathrm{s}},
\end{aligned}
$$

where $F$ is 'full income'. Eqs. (2.11) $-(2.12)$ define the Marshallian demands for the two goods. (2.10) $-(2.12)$ determine the market-clearing level of $t$, given $x^{s}$, $x^{\circ}$ and $p^{\circ}$.

\subsection{Production}

There are many industries in the o-sector, each producing a different output. Each firm is 'large' within its own industry but 'small' within the economy as a whole: each has market power in its own industry, but it does not have the general equilibrium awareness to calculate how its actions affect macroeconomic variables. ${ }^{6}$ However, in our macroeconomic model we shall formalize only one industry, which we shall take as representative of the sector. Here, we justify this approach by reference, temporarily, to the multiplicity of industries (i.e. of goods) in the economy.

Suppose that there are $J$ industries in the o-sector (where $J$ is 'large'), indexed $j=1,2, \ldots, J$. Let $p_{j}^{\mathrm{o}}$ denote the money price of the output of industry $j$ and $\mathbf{p}_{-j}^{\mathrm{o}}$ the $(J-1)$-vector of o-sector money prices other than $p_{j}^{o}$. In industry $j$ there are $n$ firms indexed $k=1,2, \ldots, n$. In each firm $k$ of industry $j$ there is increasing returns to scale, the production function being

$$
x_{k j}^{\mathrm{o}}=N_{k j}^{\mathrm{o}}-\bar{N}^{\mathrm{o}} \text {, }
$$

where $x_{k j}^{o}$ is its output and $N_{k j}^{o}$ is the employment it provides, and, following Weitzman (1982), fixed costs are an overhead labour requirement, $\bar{N}^{\circ}$.

Since preferences are homothetic the demand for industry $j$ 's output is given by

$$
x_{j}^{\mathrm{o}}=\alpha_{j}^{\mathrm{o}}\left(p_{j}^{\mathrm{o}}, \boldsymbol{p}_{-j}^{\mathrm{o}}, \boldsymbol{q}^{\mathrm{s}}\right) \cdot\left(F-\boldsymbol{q}^{\mathrm{s}} \cdot \boldsymbol{x}\right) / p_{j}^{\mathrm{o}},
$$

where $\alpha_{j}^{0}$ is the budget share function for $j, q^{\mathrm{s}}$ is the vector of s-sector goods and $\boldsymbol{x}$ is the vector of subsistence requirements. With gross substitutability $\left(\alpha_{j}^{0}\right.$ non-decreasing in $p_{j}^{o}$ ) we can invert (2.14) to obtain the Marshallian inverse demand for $j, p_{j}^{\mathrm{o}}-X_{j}\left(x_{j}^{\mathrm{o}}, \boldsymbol{p}_{-j}^{\mathrm{o}}, \boldsymbol{q}^{\mathrm{s}}, \overline{\boldsymbol{x}}, F\right)$.

\footnotetext{
${ }^{6}$ This is a common assumption (e.g., Blanchard and Kiyotaki, 1987; Dixon, 1991).
} 
Each firm $k$ in industry $j$ is assumed to adopt Cournot-Nash behaviour with respect to the industry (treating the output of other firms in the industry as fixed), but to treat the prices $\left(\boldsymbol{p}_{-j}^{\mathrm{o}}, \boldsymbol{q}^{\mathrm{s}}\right)$ of all other industries as fixed. Thus we assume that firm $k$ maximizes its money profit, $\pi_{k j}^{0}=\left(p_{j}^{0}-w\right) x_{k j}^{0}-w \bar{N}^{0}$, subject to the industry demand curve and treating the output of other firms in industry $j$ as fixed. The assumption of net money profit maximization is justified since the total number of industries (goods) is large and so the general price level and nominal national income are treated by the firm as exogenous.

Let $\epsilon_{j}^{\circ}\left(p_{j}^{\mathrm{o}}, \boldsymbol{p}_{-j}^{\mathrm{o}}, \boldsymbol{q}^{\mathrm{s}}\right)$ denote the (absolutc) clasticity of demand for $j$. With weak gross substitutability $\left(\epsilon_{j}^{0} \geqslant 1\right)$ and assuming that $\epsilon_{j}^{0}$ is non-decreasing in $p_{j}^{0}$, a unique symmetric equilibrium exists in industry $j$ (see Hart, 1982), characterized by $p_{j}^{\circ}=n \epsilon_{j}^{\circ} w /\left[n \epsilon_{j}^{\circ}-1\right]$. Since we shall focus on the representative o-sector industry we can write $p_{j}^{0}=p^{0}(j=1,2, \ldots, J)$ and, similarly, we can write $q^{s}$ for the representative s-sector price. From (2.14) $\epsilon_{j}^{0}$ is homogeneous of degree zero, and so we can define the function $\epsilon\left(p^{\circ} / q^{\mathrm{s}}\right) \equiv \epsilon_{j}^{\mathrm{o}}\left(p^{\mathrm{o}}, q^{\mathrm{s}}\right)$, where $\epsilon$ is the elasticity of demand in the typical o-sector industry, and where all 0 -sector prices are $p^{0}$ and all s-sector prices are $q^{\mathrm{s}}$. Equilibrium is therefore characterized by

$$
p^{o}=\mu\left(\frac{p^{\mathrm{o}}}{q^{\mathrm{s}}}\right) \cdot w
$$

where $\mu$ is the mark-up of $p^{\text {o }}$ over $w$; i.e., $\mu \equiv n \epsilon\left(p^{\circ} / q^{\mathrm{s}}\right) /\left[n \epsilon\left(p^{\mathrm{o}} / q^{\mathrm{s}}\right)-1\right]$. Since $\epsilon\left(p^{\circ} / q^{\mathrm{s}}\right) \geqslant 1$ and $\epsilon$ is non-decreasing, it follows that $\mu$ is non-increasing in $\left(p^{\circ} / q^{\mathrm{s}}\right)$, and, furthermore, $1>\mu \geqslant n /(n-1) . \mu$ is also homogeneous of degree zero in $\left(p^{\circ}, q^{\mathrm{s}}\right)$.

Using (2.13) and (2.15) o-sector money profit $\pi^{\circ}$ and employment $N^{\circ}$ are

$$
\begin{aligned}
& \pi^{\circ}=w\left\{\left[\mu\left(p^{\circ} / q^{\mathrm{s}}\right)-1\right] x^{\mathrm{o}}-n \bar{N}^{\mathrm{o}}\right\}, \\
& N^{\mathrm{o}}=x^{\mathrm{o}}+n \bar{N}^{\mathrm{o}} .
\end{aligned}
$$

The s-sector also consists of a number of industries each producing a different homogeneous good, but output and nominal price are predetermined for each industry. We characterize the representative industry, which contains $m$ firms, indexed $i=1,2, \ldots, m$. The production function of firm $i$ is

$$
x_{i}^{\mathrm{s}}=e N_{i}^{\mathrm{s}}-\vec{N}^{\mathrm{s}} \text {, }
$$

where $N_{i}^{\text {s }}$ is its employment, $\bar{N}^{\text {s }}$ its set-up cost and $e$ is a parameter reflecting the efficiency of the firm, which may change when market-orientated reforms are introduced. Thus,

$$
N^{\mathrm{s}}=e x^{\mathrm{s}}+m \bar{N}^{s}
$$

where $N^{s} \equiv \sum_{i=1}^{m} N_{i}^{\mathrm{s}}$ and $x^{\mathrm{s}} \equiv \sum_{i=1}^{m} x_{i}^{\mathrm{s}}$. Assuming that the state pays its employ- 
ees the same money wage rate $w$ as is paid in the o-sector, aggregate s-sector money profit is

$$
\pi^{\mathrm{s}}=\left(p^{\mathrm{s}}-e w\right) x^{\mathrm{s}}-w m \bar{N}^{\mathrm{s}} .
$$

\subsection{The labour market}

We assume that there are no trade unions. There is an excess supply of labour and so households compete for jobs, driving the real wage rate down to the disutility of labour:

$$
\frac{w}{P\left(q^{\mathrm{s}}, p^{\mathrm{o}}\right)}=\theta
$$

As we have noted, the cost-of-living depends on the full price $q^{\mathrm{s}}$. In the context of (2.21), the need to queue when buying the s-sector good reduces the value of each 'rouble' for the household. It must therefore be compensated in the form of a higher money wage rate. ${ }^{7}$

The constant real wage represented by (2.21) considerably simplifies our analysis. We have derived the constant real wage from the highly specific assumption of a constant disutility $\theta$, together with a perfectly elastic supply of labour. However, our model would be valid in any framework in which - even if $\theta$ were variable - the real wage were constant and labour supply perfectly elastic over the relevant range, e.g. in an efficiency wage model. The assumption of perfect elasticity seems appropriate given Stylized Fact No. 3.

Finally, total employment $N$ is simply the sum of employment in the two sectors:

$$
N=N^{\mathrm{o}}+N^{\mathrm{s}}
$$

\section{Equilibrium}

We assume given values for the parameters $\theta, c, n$ and $e$ and that the macro-policy tools, $\bar{M}$ and $D$, and the s-sector nominal price $p^{\mathrm{s}}$ and output $x^{\mathrm{s}}$ are fixed exogenously. The values of $N^{\mathrm{s}}, M$ and $Y$ then follow from (2.19), (2.7) and

\footnotetext{
${ }^{7}$ In practice, Russian workers have taken industrial action to try and defend their real wage. To take this into account, we might assume that $w / P\left(q^{\mathrm{s}}, p^{0}\right)$ were parametrically fixed (by institutional factors) at a level $\bar{\theta}$, where $\bar{\theta}>\theta$. The only significant effects on our analysis would be that, throughout, a higher level of $\bar{\theta}$ would be associated with a lower equilibrium level of o-sector output and a higher cost-of-living $P(\cdot)$, and in Section 5, where the s-sector is privatized, s-sector output would also be lower.
} 
(2.9) respectively. The macroeconomic equilibrium can be summarized by five equations in five unknowns $\left(p^{\mathrm{o}}, w, t, q^{\mathrm{s}}, x^{\mathrm{o}}\right)$ :

$$
\begin{aligned}
& p^{0}=\mu\left(\frac{p^{\mathrm{o}}}{q^{\mathrm{s}}}\right) \cdot w, \\
& w=\theta \cdot P\left(q^{\mathrm{s}}, p^{\mathrm{o}}\right), \\
& q^{\mathrm{s}}\left(x^{\mathrm{s}}-\bar{x}\right)=\alpha\left(\frac{p^{\mathrm{o}}}{q^{\mathrm{s}}}\right)\left[p^{\mathrm{o}} x^{\mathrm{o}}+q^{\mathrm{s}}\left(x^{\mathrm{s}}-\bar{x}\right)\right], \\
& Y=\frac{c}{1-c}(\bar{M}+D)=p^{\mathrm{s}} x^{\mathrm{s}}+p^{\mathrm{o}} x^{\mathrm{o}}, \\
& q^{\mathrm{s}}=p^{\mathrm{s}}+w t .
\end{aligned}
$$

Eqs. (3.1) and (3.2) are simply (2.15) and (2.21) respectively. Eq. (3.3) is obtained from (2.11a) and (2.11b); (3.4) follows from (2.8) and (2.9), and (3.5) is obtained from (2.10) and (2.21). Given the solution to (3.1)-(3.5), the equilibrium values of $p, \pi^{\circ}, \pi^{\mathrm{s}}, F, N^{\circ}, N, Q$ and $Z$ are found from (2.1), (2.3), (2.5), (2.12), (2.16), (2.17), (2.20) and (2.22).

The system (3.1)-(3.5) decomposes, and can be solved recursively. A sufficient condition for the existence and uniqueness of a solution is given by assumption A.1:

A.1. (a) $P(\phi, 1)$ is monotonic in $\phi$ and strictly increasing when $0<\alpha<1$.

(b) For $\phi \geqslant 0, \min P(\phi, 1)<(n-1) / n \theta$ and $\sup P(\phi, 1)>1 / \theta$.

If, for example, $U$ is Cobb-Douglas, $P(\phi, 1)=\phi^{\alpha}$ and A.1 is satisfied. If $U$ is CES, say $U=\left[\left(x^{\mathrm{s}}-\bar{x}\right)^{\rho}+\left(x^{\mathrm{o}}\right)^{\rho}\right]^{1 / \rho}, P(\phi, 1)=\left(\phi^{r}+1\right)^{1 / r}$, where $r=\rho /(1$ $-\rho)$, and A.1 is satisfied only if $\theta<(n-1) / n$. This does not seem an onerous restriction, particularly since A.1 is a sufficient condition.

Proposition 1. The full-price ratio $q^{\mathrm{s}} / p^{0}$ is uniquely determined from (3.1)-(3.2)

Proof. From (3.1)-(3.2) and the degree-one homogeneity of $P$ we obtain

$$
\mu\left(\frac{p^{\circ}}{q^{\mathrm{s}}}\right) \theta P\left(\frac{q^{\mathrm{s}}}{p^{\circ}}, 1\right)=1 .
$$

$P$ and $\mu$ are continuous, and $1>\mu \geqslant n /(n-1)$; hence by A.1 there exists a unique solution. Q.E.D.

Proposition 2. Oligopolistic sector output is proportional to the excess of state-controlled sector output over the subsistence level

$$
x^{0}=\frac{q^{\mathrm{s}}}{p^{0}} \cdot\left(\frac{1-\alpha}{\alpha}\right)\left(x^{\mathrm{s}}-\bar{x}\right) .
$$


Proof. From Proposition $1, q^{\mathrm{s}} / p^{\circ}$ is determined and hence so is $\alpha$. Eq. (3.7) follows from rearranging (3.3). Q.E.D.

Proposition 2 does not rely on the assumption of nominal price rigidity in the s-sector; rather, what matters is the fixity of output $x^{\mathrm{s}}$. (We shall see in Section 4 that the proportionality result of the proposition also holds when $p^{\mathrm{s}}$ is liberalized, given that $x^{\mathrm{s}}$ is still predetermined). The proposition gives rise to a 'Classical' property that, for given $x^{5}$, the economy possesses a Natural Rate, with output and employment fixed. However, in another sense the result is 'Keynesian', for there is general equilibrium complementarity between 0 - and s-sector outputs. An increase, say, in the excess of s-sector output over $\bar{x}$ will result in a proportionate increase in o-sector output. Intuitively, if $x^{\mathrm{s}}$ is greater, the full price $q^{\mathrm{s}}$ that the household is willing to pay becomes lower. This causes $w$ (which is based on the cost-of-living) to become lower. Since $p^{\circ}$ is a mark-up on $w, p^{\circ}$ also becomes lower and a greater amount of o-sector output is sold at this price. There are further repercussions, but in equilibrium the price ratio $q^{\mathrm{s}} / p^{\circ}$ is restored. The result is valid given our assumption that homogeneous labour, which is in excess supply, is the only variable input. If, alternatively, we assumed that the s-sector tied up factors such as skilled labour and capital that were in shortage in the o-sector then more standard crowding-out arguments would apply.

Proposition 2 may be considered in the context of the output decline experienced in practice. As Borensztein et al. (1993) note, this decline was occurring before communism ended, as well as in the ensuing transition. Our analysis indicates that the forces at work may have been more complicated than may initially be apparent. Although the state and private sectors may also compete for resources in short supply, our complementarity result shows that, through a general equilibrium chain reaction, the fall in state sector output that occurred in practice may actually have inhibited the development of private sector industry.

Since we have determined $x^{\circ}$ from (3.7) we can solve for $p^{\circ}$ from (3.4). Taking into account that $q^{\mathrm{s}} / p^{\circ}$ is fixed, we can then determine $q^{\mathrm{s}}$ from (3.6). The equilibrium values of $w$ and $t$ then follow from (3.2) and (3.5). 8

\section{Proposition 3. An 'almost' Classical dichotomy}

(a) The real variables $\left(x^{\mathrm{o}}, q^{\mathrm{s}} / p^{\circ}\right)$ are determined by $\left(\theta, x^{\mathrm{s}}, \bar{x}, \alpha, n\right)$

(b) The real variables $(t, Q)$ are determined by $\left(\theta, x^{\mathrm{s}}, \bar{x}, \alpha, c, D, \bar{M}, p^{\mathrm{s}}\right)$

The real variables $x^{\mathrm{n}}$ and $q^{\mathrm{s}} / p^{\mathrm{n}}$ are determined independently of the 'money'

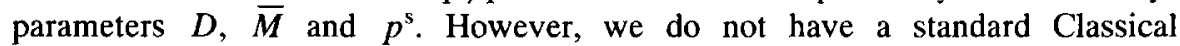
Dichotomy because the real variables $t$ and $Q$ depend on $D, \bar{M}$ and $p^{\mathrm{s}}$. This

\footnotetext{
${ }^{8}$ Under A.1, a unique solution exists to (3.1)-(3.5). It is only an equilibrium if $Z \geqslant 0$, i.e., if the equilibrium $t$ is small enough to satisfy $x^{5}+N^{5}+N^{0} \leqslant H$.
} 
dependence occurs because of the nominal price rigidity for the s-sector good; effort expended in queuing and search therefore acts as a 'price' variable to 'clear' the s-sector market. Full price clears the market in a Classical sense, but real resources are used up (leisure is forgone). (If, alternatively, we were to assume real price rigidity, say with $p^{\mathrm{s}}$ indexed to $w$, the full Classical Dichotomy would re-emerge.)

\subsection{Monetary expansion}

In a transitional economy money prices for many goods are higher than under communism. The government may therefore find it politically expedient to offer some monetary compensation to households, e.g., higher money pensions and other benefits. Although our model is not well suited to analyzing distributional issues, it reveals interesting macroeconomic effects of setting initial money holdings $\bar{M}$ (or the deficit $D$ ) at a higher level.

Proposition 4. A monetary expansion (or larger budget deficit) causes full prices to respond more than equi-proportionately and reduces welfare.

Proof. From (2.2), $u$ is a function of $\left(x^{\mathrm{s}}, x^{\mathrm{o}}, M / p, N, Q\right)$. An increase in $\bar{M}+D$ has no effect on $x^{\mathrm{s}}$ (fixed by assumption) or on $x^{0}$ (from Proposition 2). Since $x^{\circ}$ and $x^{\mathrm{s}}$ are fixed, so is $N$. But the increase in $\bar{M}+D$ does affect $M / p$ and $Q$. From (3.3) and (3.4), $\mathrm{d} \ln q^{\mathrm{s}} / \mathrm{d} \ln (\bar{M}+D)=Y /\left(Y-p^{\mathrm{s}} x^{\mathrm{s}}\right)>1$. Using (3.2) and the degree-one homogeneity of $P$, we therefore have that $q^{\mathrm{s}}, p^{\circ}, P$ and $w$ all rise in equal proportions, but by more, proportionately, than $\bar{M}+D$. Thus, from (3.5), since $p^{\mathrm{s}}$ is fixed, $t$ rises, as therefore does $Q\left(=t x^{\mathrm{s}}\right)$. Also, since $M=\bar{M}+D$ (eq. (2.7)), $M / P$ falls. Because $Q$ rises and $M / P$ falls, $u$ falls. $\quad$ Q.E.D.

Intuitively, when the household has more money it increases its goods demands. Since $x^{\mathrm{s}}$ is fixed, unit queuing time $t$ (and so also $q^{\mathrm{s}}$ ) rises, adversely affecting welfare. As $x^{\circ}$ is tied to $x^{\mathrm{s}}$ (Proposition 2), it too is unchanged and so $p^{\circ}$ rises. But, from (3.4), as $p^{\mathrm{s}}$ is also fixed, a $1 \%$ increase in $\bar{M}+D$ is associated with a more than $1 \%$ increase in $p^{\circ}$. To keep $p^{\circ} / q^{\mathrm{s}}$ unchanged (Proposition 1) $q^{\mathrm{s}}$ must rise by more than $1 \%$, as therefore do $P(\cdot)$ and $w$. We shall refer to the more than proportionate response of $q^{\mathrm{s}}, q^{\mathrm{o}}, P(\cdot)$ and $w$ to a rise in $\bar{M}+D$ as the 'over-inflationary' property of such an economy. ${ }^{9}$

\footnotetext{
${ }^{9}$ Proposition 4 is a comparative static result referring onto changes in the level of $\bar{M}$. In a dynamic model the higher inflation caused by greater monetary growth might lead to a reduction in the demand for real balances. This would add to the inflationary pressure, particularly under conditions of hyperinflation (see Cagan, 1956). We would like to thank an anonymous referee for pointing this out.
} 
Proposition 4 is closely related to Proposition 3 . If we changed our assumption from nominal to real rigidity of $p^{s}$ then (with the full Classical Dichotomy holding) monetary expansion would have no real effects. With nominal rigidity, however, welfare is raised by a confiscatory monetary reform that reduces $\bar{M}$ (as has commonly been proposed for the early stages of transition - see IMF et al., 1991). ${ }^{10}$

\section{Price liberalization}

Price liberalization has been modelled formally in a number of recent contributions, including Kemp and Van Long (1990), Bennett and Boycko (1995), Boycko (1992), Fender and Laing (1992), Osband (1992) and Bennett (1994). However, none of these allow for the role of imperfect competition which, as we have argued, is an essential feature of transitional economies. We shall assume that s-sector employment $N^{s}$ is predetermined and we shall interpret price liberalization as a freeing of the nominal price for the s-sector good, so that it becomes market-clearing for the output that can be produced with the given level of $N^{\mathrm{s}}$. This is a narrow interpretation of liberalization, but it seems relevant to economies such as Russia in the mid-1990s. Although privatization or commercialization is an overriding objective for most goods, price-setting policy for necessities and politically-sensitive goods is unresolved. It might appear that the authorities face a dilemma; price controls are inefficient, but price liberalization is inflationary. Our analysis will shed some light on this issue.

Price liberalization eliminates queuing $(t=0)$ and so the virtual parts of the full price $q^{s}$ and full income $F$ disappear. Eq. (3.5) is no longer relevant and in (3.1)-(3.4) we can replace $q^{\mathrm{s}}$ and $p^{\mathrm{s}}$ by the liberalized money price $\mathrm{p}^{\mathrm{sL}}$. In place of (3.1)-(3.5) we have

$$
\begin{aligned}
& p^{\mathrm{oL}}=\mu\left(\frac{p^{\mathrm{oL}}}{p^{\mathrm{sL}}}\right) \cdot w^{\mathrm{L}}, \\
& w^{L}=\theta \cdot P\left(p^{\mathrm{sL}}, p^{\mathrm{oL}}\right), \\
& p^{\mathrm{sL}}\left(x^{\mathrm{sL}}-\bar{x}\right)=\alpha\left(\frac{p^{\mathrm{oL}}}{p^{\mathrm{sL}}}\right)\left[p^{\mathrm{oL}} x^{\mathrm{oL}}+p^{\mathrm{sL}}\left(x^{\mathrm{sL}}-\bar{x}\right)\right], \\
& Y=\frac{c}{1-c}(\bar{M}+D)=p^{\mathrm{sL}} x^{\mathrm{sL}}+p^{\mathrm{oL}} x^{\mathrm{oL}},
\end{aligned}
$$

\footnotetext{
${ }^{10}$ Similar results are obtained by Weitzman (1991), Boycko (1992), Osband (1992) and Bennett (1994).
} 
where the superscript $\mathrm{L}$ denotes the equilibrium value when there is liberalization. (4.3) is the s-sector market-clearance condition; sufficient for solution of (4.3), given $\mathrm{p}^{\mathrm{oL}}$, is that goods are gross substitutes $\left(\alpha^{\prime}>0\right)$. Nominal national income $Y$ is the same as in Section 3. By assumption, $e^{\mathrm{L}} \geqslant e$ : price liberalization may be associated with a rise in X-efficiency. Thus, $x^{\mathrm{sL}} \geqslant x^{\mathrm{s}}$.

Proposition 5. The effects of price liberalization:

$$
\begin{aligned}
& \frac{p^{\mathrm{sL}}}{p^{\mathrm{oL}}}=\frac{q^{\mathrm{s}}}{p^{\mathrm{o}}} \\
& \left(p^{\mathrm{sL}}, p^{\mathrm{oL}}, w^{L}\right)=\lambda\left(q^{\mathrm{s}}, p^{\mathrm{o}}, w\right) \quad \text { where } \\
& \quad \lambda=\left(\frac{x^{\mathrm{s}}-\bar{x}}{x^{\mathrm{sL}}-\bar{x}}\right)\left(\frac{Y-p^{\mathrm{sL}} \bar{x}}{Y-p^{\mathrm{s}} x^{\mathrm{s}}+q^{\mathrm{s}}\left(x^{\mathrm{s}}-\bar{x}\right)}\right)<1 ; \\
& \text { If } e^{L}=e, x^{\mathrm{oL}}=x^{\mathrm{o}} ; \text { if } e^{L}>e, x^{\mathrm{oL}}>x^{\mathrm{o}} .
\end{aligned}
$$

Proof. (a) Instead of (3.6) we have

$$
\mu\left(\frac{p^{\mathrm{oL}}}{p^{\mathrm{sL}}}\right) \theta P\left(\frac{p^{\mathrm{sL}}}{p^{\mathrm{oL}}}, 1\right)=1 .
$$

Comparing (4.5) with (3.6), (a) follows.

(b) Because of (a), $\alpha\left(p^{\circ} / q^{\mathrm{s}}\right)=\alpha\left(p^{\mathrm{oL}} / p^{\mathrm{sL}}\right)$ and so, using (3.3), (3.4), (4.3) and (4.4), $p^{\mathrm{sL}}=\lambda q^{\mathrm{s}}$. From (a), this implies that $p^{\mathrm{oL}}=\lambda p^{\circ}$ and, since $P(\cdot)$ is homogeneous of degree one, it follows from (3.2) and (4.2) that $w^{\mathrm{L}}=\lambda w$. Sufficient for $\lambda<1$ is that $p^{\mathrm{sL}}>p^{\mathrm{s}}$ and $x^{\mathrm{s}}>\bar{x}$, which we assume true.

(c) Rearranging (4.3), $x^{\mathrm{oL}}=[(1-\alpha) / \alpha]\left(p^{\mathrm{sL}} / p^{\mathrm{oL}}\right)\left(x^{\mathrm{sL}}-\bar{x}\right)$. Comparing this with (3.7) and using (a), (c) follows. Q.E.D.

The full-price ratio that holds in the model with queuing equals the money-price ratio that holds when there is price liberalization. Of course, the liberalized money price $p^{\text {sL }}$ (which is also the with-liberalization full price) exceeds the no-liberalization money price $p^{\mathrm{s}}$, but $p^{\mathrm{sL}}$ is less than the no-liberalization full price $q^{\mathrm{s}}$ $\left(p^{\mathrm{s}}<p^{\mathrm{sL}}<q^{\mathrm{s}}\right)$. Price liberalization is disinflationary in terms of the money price for o-sector output and the money usage rate $w$ (though the real wage is constant). However, o-sector output (and employment) is only affected if $e^{\mathbf{L}}>e$. Intuitively, since the liberalized money price for s-sector output, $p^{\mathrm{sL}}$, exceeds the repressed money price, $p^{\mathrm{s}}$, total money expenditure on s-sector output is greater with liberalization than without. With liberalization, therefore, less is available to spend on o-sector output, and so the money price in the o-sector is reduced. With lower full prices the money wage rate also falls to maintain the real wage at $\theta$. If $e^{\mathrm{L}}>e$, liberalization raises o-sector output because of Proposition 2. 
Proposition 6. The real effects of price liberalization are that queuing disappears, welfare increases, and, if s-sector efficiency increases, output in both sectors rises.

Proof. To determine the welfare effect we must consider the values taken by each argument of the utility function with and without liberalization.

Suppose first that $e^{\mathrm{L}}=e$, so that $x^{\mathrm{sL}}=x^{\mathrm{s}}$. Hence, from Proposition 5(c) $x^{\mathrm{oL}}=x^{\mathrm{o}}$ and $N^{\mathrm{oL}}=N^{\mathrm{o}}$. By assumption $N^{\mathrm{sL}}=N^{\mathrm{s}}$, and so $N^{\mathrm{L}}=N$, while queuing only occurs without liberalization. The remaining argument of the utility function is the real terminal balance, $M^{\mathrm{L}} / P\left(p^{\mathrm{sL}}, p^{\mathrm{oL}}\right)$ with liberalization and $M / P\left(q^{\mathrm{s}}, p^{\circ}\right)$ without. From (2.7), $M=M^{\mathrm{L}}=\bar{M}+D$. Also, from Proposition 5(b), $P\left(p^{\mathrm{sL}}, p^{\mathrm{oL}}\right)=\lambda P\left(q^{\mathrm{s}}, p^{\circ}\right)$, where $\lambda<1$. Thus, $M / P\left(q^{\mathrm{s}}, p^{\circ}\right)<$ $M^{\mathrm{L}} / P\left(p^{\mathrm{sL}}, p^{\mathrm{oL}}\right)$; i.e., the real terminal balance is greater with liberalization. However, the reason for this difference is purely that $P\left(q^{\mathrm{s}}, p^{\mathrm{o}}\right)>P\left(p^{\mathrm{sL}}, p^{\mathrm{oL}}\right)$ : the terminal money balance is deflated by more in the no-liberalization case because queuing in the future (which the household assumes will be necessary) makes each rouble worth less in terms of utility. If it were not for the need to spend time queuing in the future the real terminal balance would be the same in each regime. Thus, if $e=e^{\mathrm{L}}$, it is only because of the disappearance of queuing (today and through its effect on real terminal balances) that welfare rises.

If $e^{\mathrm{L}}>e, x^{\mathrm{sL}}>x$. Since $N^{\mathrm{sL}}=N^{\mathrm{s}}$, welfare rises. Also from Proposition $5(\mathrm{c})$, $x^{\mathrm{oL}}>x^{\mathrm{O}}$ and $N^{\mathrm{oL}}>N^{\mathrm{o}}$ causing a further rise in welfare (due to imperfect competition the marginal value of output exceeds the marginal social cost of output $\left.\left(p^{\circ} / P>\theta\right)\right)$. Q.E.D.

Proposition 6 is robust to the following change of assumption. Following Bennett and Boycko (1995) and Fender and Laing (1992), suppose that although there is a choice for the government between a liberalized s-sector price and a repressed one in the current period, the liberalized price is sure to be set in the next period. This approach captures the notion that the economy is moving towards a liberalized state, and the only policy issue is how soon to move in terms of price. In this case the terminal money balance should be deflated by the liberalized price irrespective of whether there is liberalization now.

Proposition 7. Monetary expansion (or an increased budget deficit) in a priceliberalized economy has an equi-proportionate effect on prices and has no effect on welfare.

Proof. From Propositions 1 and 5(a), $p^{\mathrm{sL}} / p^{\mathrm{oL}}$ is independent of $\bar{M}+D$. From (4.4), with $x^{\mathrm{s}}$ and $x^{\mathrm{oL}}$ constant (Proposition 5(c)), $p^{\mathrm{sL}}$ and $p^{\mathrm{oL}}$ rise in the same proportion as $\bar{M}+D$. Thus, $P(\cdot)$ and $w^{\mathrm{L}}$ will rise in this proportion.

Given that $M^{L}=\bar{M}+D$, real terminal holdings $M^{\mathrm{L}} / P(\cdot)$ are therefore unaffected by the change in $\bar{M}+D$. Since $x^{\mathrm{s}}$ and $x^{\mathrm{oL}}$ are constant, $N^{L}$ is constant; 
and, by assumption, $Q^{\mathrm{L}}=0$. Thus, none of the arguments of $u$ is affected. Q.E.D.

Thus, there is a sense in which the liberalized economy is less inflationary than the unliberalized economy. In contrast to the 'over-inflation' that results from a higher money supply in the unliberalized economy (with nominal $p^{\mathrm{s}}$-rigidity), prices in the liberalized economy follow the Classical Dichotomy, rising equi-proportionately with the money supply.

\section{Privatization}

How will the process of privatization influence the behaviour of the transitional economy? Since the state-controlled sector in our model produces necessities $(\bar{x}>0)$, privatization creates a situation in which large monopoly profits may be made. Such privatized industries will almost certainly require regulation. We model privatization as a shift to regime in which the post-privatization nominal price $\mathrm{p}^{\mathrm{sP}}$ will be restricted:

$$
p^{\mathrm{sP}} \leqslant \bar{p}
$$

We assume that the price-cap $\bar{p}$ is binding but is chosen such that production is profitable, that is, such that $p^{\mathrm{sP}}$ exceeds the marginal cost of s-sector production, $w$. The privatized s-sector firms will therefore always meet the demand $x^{\mathrm{sP}}$ at the price $p^{\mathrm{sP}}$. This is analogous to the analysis of price controls in the Israeli economy by Helpman (1988).

With privatization, s-sector profit, nct of tax, accrues to the household; but it is easily checked that nominal national income is still given by Eq. (2.9). The equilibrium equations are therefore the same as (4.1)-(4.4), except that we must replace $p^{\mathrm{oL}}, p^{\mathrm{sL}}$ and $x^{\mathrm{s}}$ by $p^{\mathrm{oP}}, p^{\mathrm{sP}}$ and $x^{\mathrm{sP}}$, respectively, where the superscript $\mathrm{P}$ denotes the value under privatization.

Proposition 8. The spillover effect in a privatized economy:

$$
\begin{aligned}
& \frac{p^{\mathrm{sP}}}{p^{\mathrm{UP}}}=\frac{p^{\mathrm{sL}}}{p^{\mathrm{UL}}} \\
& x^{\mathrm{oP}}=\left(\frac{1-\alpha}{\alpha}\right)\left(\frac{p^{\mathrm{sP}}}{p^{\mathrm{UP}}}\right)\left(x^{\mathrm{sP}}-\bar{x}\right) .
\end{aligned}
$$

Proof. (a) With privatization, instead of (4.5) we have

$$
\mu\left(\frac{p^{\mathrm{oP}}}{p^{\mathrm{sP}}}\right) \theta P\left(\frac{p^{\mathrm{sP}}}{p^{\mathrm{oP}}}, 1\right)=1 .
$$




\section{Comparing (5.2) with (4.5) gives (a). (b) follows by analogy with Proposition 2. Q.E.D.}

In an economy with privatization there is therefore a spillover effect on to the o-sector: a higher (lower) output in the s-sector after privatization has a general equilibrium knock-on effect, resulting in a higher (lower) o-sector output. The mechanism by which this occurs is that if, say, the nominal price $p^{\mathrm{sP}}$ is set higher, $s$-sector output will be lower. With fixed relative prices $p^{\mathrm{oP}}$ must therefore be higher; but goods demands are unit-elastic and so $x^{\mathrm{nP}}$ must be lower. ${ }^{11}$ This suggests that when privatization occurs the government should not at the same time run down the firms remaining under state control; rather, privatization should be accompanied by policies to stimulate output, in particular by low price caps. Taken together, Propositions 2 and 8 indicate that, irrespective of ownership of the s-sector, there is a macroeconomic case for building up its output.

It is also interesting to compare the effects of monetary expansion in this type of economy with the effects in the economies with queuing and with price liberalization.

Proposition 9. If the s-sector is privatised, but subject to nominal price-cap regulation, monetary expansion leads to higher output in each sector.

Proof. With privatization, (4.4) becomes

$$
Y=\left(\frac{c}{1-c}\right)(\bar{M}+D)=p^{\mathrm{sP}} x^{\mathrm{sP}}+p^{\mathrm{oP}} x^{\mathrm{oP}} .
$$

With $p^{\mathrm{sP}}$ given by the price cap, it follows from Proposition $8(\mathrm{a})$ that $p^{\mathrm{oP}}$ is fixed. From (5.3), (2.11b) and (4.3) (rewritten with P-superscripts) we obtain

$$
\begin{aligned}
& O<\frac{\mathrm{d} x^{\mathrm{sP}}}{\mathrm{d}(\bar{M}+D)} \cdot \frac{\bar{M}+D}{x^{\mathrm{sP}}}=\frac{\alpha Y}{(1-\alpha) p^{\mathrm{sP}} \bar{x}+\alpha Y}<1 ; \\
& \frac{\mathrm{d} x^{\mathrm{oP}}}{\mathrm{d}(\bar{M}+D)} \cdot \frac{(\bar{M}+D)}{x^{\mathrm{oP}}}=\frac{Y}{Y-p^{\mathrm{sP}} \bar{x}}>1 .
\end{aligned}
$$

If $\bar{x}$ were zero, both elasticities would equal 1 ; but the greater is $\bar{x}$, the more the elasticities deviate from 1. Q.E.D.

A monetary expansion raises the nominal demands for goods. But with $p^{\mathrm{sP}}$ set by the nominal price-cap and with relative prices fixed, $p^{\mathrm{oP}}$ (and $w$ ) is therefore

\footnotetext{
${ }^{11}$ We make this argument for a given level of the post-privatization efficiency parameter $e^{\mathrm{sP}}$. We are assuming in this section that demand is satisfied for the given price-cap. If $e^{\mathrm{sP}}$ is higher then $N^{\mathrm{sP}}$ is smaller for the given output, but there are no further macroeconomic repercussions.
} 
fixed. Hence, outputs rise. In contrast to the price-liberalized economy which responds in a Classical manner, with no output effects, the privatized economy behaves in a 'Keynesian' fashion. Whereas Blanchard and Kiyotaki (1987), for example, obtain this type of result by modelling menu costs, in our model it stems from price regulation, as in Helpman (1988). Note that even if the regulation extends to only a relatively small part of the economy, monetary expansion has a positive output effect throughout the economy, and, indeed, the elasticity of this effect is greater outside the s-sector.

Finally, suppose instead that there is real price-cap regulation. We might, for example, have the restriction that $p^{\mathrm{sP}} \leqslant K p^{\mathrm{sL}}(K>0)$. This is a real rigidity, setting the price-cap relative to the price $p^{\text {sL }}$ that would prevail in a free market, which, from Proposition 7 , is proportional to $\bar{M}+D .{ }^{12}$ Assuming that $K$ is chosen such that the price-cap is binding, but production is profitable, Proposition 8 is still found to hold. However, the underlying homogeneity of the system is restored and so, instead of Proposition 9, we have that money is neutral. Hence, whilst in the short run price-cap regulation can give rise to Keynesian features, if the price-cap is indexed the long-run properties are Classical.

\section{Concluding comments}

This paper has considered a simple general equilibrium model of a transitional economy which takes into account four stylized facts, and in particular the high degree of market power that is a legacy of communist central planning. The main implications of the model for policy are the following.

First, in the model with queuing it is misleading to use money prices as diagnostic indicators in the way that one might in a free market economy; rather, we need to look at full prices inclusive of the cost of queuing. Whilst price liberalization in the state-controlled sector is associated with a higher money price for the sector's output, it actually reduces full price. Indeed, such price liberalization is also disinflationary with respect to the money wage rate and the (money or full) price in the oligopolistic sector, and it raises household welfare. In our model, therefore, the question posed by Kaser (1990) and the IMF et al. (1990), among others, of whether price liberalization should precede domonopolization, is answered in the affirmative. Furthermore, our analysis indicates that the government should avoid indexation of the money wage rate to money prices, which would be highly distortionary.

Second, the effects of monetary expansion (or a greater budget deficit) depend systematically on whether liberalization has occurred and on the form of liberalization. With price liberalization in the state-controlled sector the Classical Di-

\footnotetext{
${ }^{12}$ We are grateful to a referee for pointing this out.
} 
chotomy holds: prices rise by the same proportion as the money supply. Without price liberalization, however, monetary expansion is 'super-inflationary': speaking in terms of the full price for the state-controlled sector, prices and money wages rise by more, proportionately, than the money supply. In this sense an economy with some prices repressed is more inflationary than a price-liberalized economy. Yet if the state-controlled sector is privatized, with a binding nominal price-cap, monetary expansion has positive real effects, the effect being stronger, proportionately, in the oligopolistic sector. A general implication of these results is that the early phase of the transition is the time when a tight monctary stance may be of particular importance.

Third, a feature of the model is the general equilibrium complementarity between the oligopolistic and state-controlled sector outputs. This has an important policy implication: rather than running down the state-controlled sector, governments should expand it, thereby encouraging output throughout the economy. And if the state-controlled sector is privatized, there must be an associated increase in its output if there are to be positive effects on the rest of the economy. Of course, in practice there are many complications, such as shortage of critical inputs, which might lead to contrary effects. But our concern is to emphasize the existence of a path of causation, via the adjustment of full price and the money wage rate, which can easily be neglected in policy debates.

\section{Acknowledgment}

We would like to thank three anonymous referees, whose constructive criticisms have led to significant improvements in the paper. We also are grateful for helpful comments by Christopher Heady, Phillip Lawler, and seminar participants at the Universities of Bath, Oxford, Reading and Stirling.

\section{References}

Aslund, A., 1993, The gradual nature of economic change in Russia, in: A. Aslund and R. Layard, eds., Changing the economic system in Russia (Pinter, London).

Bennett, J., 1994, Queuing and the price level under repressed inflation, Oxford Economic Papers 46, $68-82$.

Bennett, J. and M. Boycko, 1995, Savings and stabilization policy in a pre post-socialist economy, Journal of Money, Credit and Banking, forthcoming.

Bennett, J. and H. Dixon, 1993, Macroeconomic equilibrium and reform in a transitional economy, Discussion paper no. 758 (CEPR, London).

Blanchard, O. and N. Kiyotaki, 1987, Monopolistic competition and the effects of aggregate demand, American Economic Review 77, 647-666.

Burenszlein, E., D.G. Demekas and J.D. Ostroy, 1993, An empirical analysis of output declines in three Eastern European countries, IMF Staff Papers 40, 1-31.

Boycko, M., 1992, When higher incomes reduce welfare: Queues, labor supply and macro equilibrium in Soviet-type economies, Quarterly Journal of Economics 107, 902-920. 
Cagan, P., 1956, The monetary dynamics of hyperinflation, in: M. Friedman, ed., Studies in the quantity theory of money (University of Chicago Press, Chicago, IL).

Dixon, H., 1991, Macroeconomic policy in a large unionised economy, European Economic Review $35,1427-1448$.

Doyle, C., 1993, The distributional consequences of Russia's transition, Discussion paper no. 839 (CEPR, London).

Estrin, S. and P. Hare, 1992, Firms in transition: Modelling enterprise adjustment, Discussion paper no. 89 (Centre for Economic Performance, LSE, London).

Feltenstein, A. and Z. Farhidian, 1987, Fiscal policy, monetary targets, and the price level in a centrally planned economy: An application to China, Journal of Money, Credit and Banking 19, 137-156.

Feltenstein, A. and J. Ha, 1991, Measurement of repressed inflation in China, Journal of Development Economics 36, 279-294.

Feltenstein, A., D. Lebow and S. van Wijnbergen, 1990, Savings, commodity market rationing and the real rate of interest in China, Journal of Money, Credit and Banking 22, 234-252.

Fender, J. and D. Laing, 1992, The transition from central planning: An intertemporal macroeconomic model, Mimeo. (Pennsylvania State University, University Park, PA).

Hare, P. and T., Révész, 1992, Hungary's transition to the market: The case against a 'big-bang', Economic Policy 14, 227-264.

Hart, O., 1982, A model of imperfect competition with Keynesian features, Quarterly Journal of Economics 97, 109-138.

IIelpman, E., 1988, Macroeconomic effects of price controls: The role of market structure, Economic Journal 98, 340-354.

IMF, 1992, World Economic Outlook, (a) May and (b) October.

IMF, The World Bank, OECD and EBRD, 1991, A Study of the Soviet Economy, 3 Volumes.

Kaser, M., 1990, The technology of decontrol, Economic Journal 100, 596-615.

Kemp, M.C. and N. Van Long., 1990, The relaxation of price controls, the general price level and welfare, Journal of Macroeconomics 12, 221-246.

Kornai, J., 1990, The road to a free economy, shifting from a socialist economy: The example of Hungary (Norton, New York).

Kroll, H., 1991, Monopoly and transition to the market, Soviet Economy 143-174.

Landesmann, M. and I. Székeley, 1991, Industrial restructuring and the reorientation of trade in Czechoslovakia, Hungary and Poland, Discussion paper no. 546 (CEPR, London).

Lipton, D. and J. Sachs, 1990, Creating a market economy in Eastern Europe: The case of Poland, Brookings Papers on Economic Activity, 75-133.

OECD, 1992, Economic Outlook (Paris) Dec.

Osband, K., 1992, Economic crisis in a shortage economy, Journal of Political Economy 100, 673-690.

Portes, R. and A. Santorum, 1987, Money and the consumption goods market in China, Journal of Comparative Economics 11, 334-353.

Russian Economic Trends, 1992, Vol 1, no. 3 (Whirr Publishers, London).

Sah, R.K., 1987, Queues, rations and the market: Comparisons of outcomes for the poor and the rich, American Economic Review 77, 69-77.

Stahl, D.O. II, and M. Alexeev, 1985, The influence of black markets on a queue-rationed centrally planned economy, Journal of Economic Theory 35, 234-250.

Weitzman, M.L., 1982, Increasing returns and the foundations of unemployment theory, Economic Journal 92, 787-804.

Weitzman, M.L., 1991, Price distortion and shortage deformation, or what happened to the soap?, American Economic Review 81, 401-414. 